\title{
Tropical Imaginaries in Living Cities
}

\author{
Anita Lundberg
}

James Cook University Singapore

\begin{abstract}
This is the second part of the eTropic special issue theme on Tropical Imaginaries and Living Cities. While the first part of this series concentrated predominately on concrete cities and the material imagination, this second issue explores notions of the tropics and cities through literary and artistic works. Thus in this collection of papers the tropical imaginary comes to the forefront while the metropolis provides the space or canvas for the imagination.

Many of the cities called up in this collection have physical presence, places such as Darwin, Singapore, Hong Kong, Shanghai, Paris, Berlin, Venice, Havana, and Kuching. Other cities conjured here may morph into various otherworldly forms such as haunted spaces or spaceships; or dissolve into a hazy backdrop as memory and imagination take the stage. Yet these urban spaces are nevertheless always alive, their virtual presence becomes the matrix that holds the imagination. The literary and creative works examined here flow from martial arts, through literary works including novels, short stories, poetry, and speculative fiction, and then transition into visual art through science-fiction magazine covers, art on walls and heritage arts spaces, to come to a close with film.
\end{abstract}

Keywords: tropics, cities, imagination, feminism, literature, poetry, martial arts, visual arts, digital humanities, ecology, film 
67 ropical Imaginaries in Living Cities' is the second part of the eTropic special issue on tropical imaginaries as they are evoked in and through the life of the city. While the first part of this series concentrated predominately on concrete cities and material imagination (Lundberg, 2018), the second part to this theme conjures notions of the tropics and of cities through literary and artistic works. Thus the tropical imaginary comes to the forefront while the metropolis provides the space or canvas for the imagination.

This collection of papers calls up cities such as Darwin, Singapore, Hong Kong, Shanghai, Hangzhou, Paris, Berlin, Venice, Huanchaco in Peru, Valparaiso in Chile, Havana in Cuba, and Kuching in Sarawak. At other times cities morph into various otherworldly forms such as haunted spaces or spaceships; or dissolve into a hazy backdrop as memory and imagination take the stage. Yet these urban spaces are nevertheless always alive, their invisible virtual presence becomes the matrix that holds the imagination.

These cities of the imagination are never islands unto themselves, they arise out of their geographical and cultural locations. Thus the regions that inform these papers include: Northern Australia, Singapore, Peninsular Malaysia, the island of Borneo, Europe, South America, the Caribbean, China and Hong Kong - as well as literary spaces of apocalyptic vision or the outer space regions of science fiction.

Theoretically the papers engage with eastern philosophy through martial arts, phenomenology, embodiment, gothic studies, postcolonial studies, literary analysis, film analysis, mythology, ecocriticism, creative non-fiction, poetics, archetypal psychology, cultural theory, diaspora studies, Caribbean studies, mythology, critical aesthetics, feminism, digital humanities and the theory-method of flânerie.

The literary and creative works encountered in this issue flow from martial arts, through to literary works including novels, short stories, poetry, and speculative fiction. The collection transitions to visual art through science-fiction magazine covers and on to wall art and heritage arts spaces. The collection closes with the film screen.

In the opening paper Lian Sutton introduces us to the Malay Martial Art of Silat Tua. He discusses this tradition in relation to the tropical regions of the Malaysian Peninsula and Singapore and delves into the imagery work of the four elements - Earth, Water, Fire, and Wind - inherent to this practice. These elements are also the inspiration of the early phenomenological philosophy, or material poetics (Lundberg, 2008), of Gaston Bachelard. Sutton demonstrates a flow between this western oeuvre and eastern 
embodied art, while a video link showing the author demonstrating Silat Tua offers readers a visualization of the elements in physical action. In the legend of Silat Tua's origin - accompanied with illustrations by artist Prunella Ong - the first proponent of this martial art is believed to have gained inspiration and lessons from the inhabited environment. Thus nature is both the inspiration and impetus for movement and life, and Silat Tua's elements training in Singapore offers a way of navigating through the constant changes of city life.

The Malay Peninsula is likewise the setting of Sathyabhama Daly's paper which explores how cultural narratives of haunted spaces and ghosts are used to articulate the impact of colonisation on the former Malaya. Three literary works reveal the ambivalence between indigenous spiritual beliefs of Malays, Chinese, and Indians with the encroaching British religious faith of Christianity and Catholicism. Beth Yahp's The Crocodile Fury (1992) is set in a convent in the liminal realm between jungle and urban environment where ghosts of the colonial past vie with those of local spirits. Here the convent is invoked as a "civilised space"; the jungle as an imposing wilderness haunted by Chinese gods and the Malay female vampire ghost Pontianak. Again, in K.S. Maniam's collection of short stories under the title Haunting the Tiger (1996), the setting invokes the liminal space between city and jungle to express the supernatural and abject in the metaphorical exile experienced by the Indian and Chinese diaspora in Malaysia. Yet, the trope of liminality is most evidently expressed through Shirley Lim's collection of short stories entitled Life's Mysteries (1995), here domestic and urban spaces are viewed through the optics of imprisonment and disempowerment. Sathyabhama Daly argues that through gothic themes of shadows, darkness and the underworld the authors portray the psychological and social-cultural exile experienced by colonised peoples.

Hannah Lutchmansingh's paper takes us to the Caribbean to explore the psycho-social impacts of empire and exile on black female bodies through an analysis of the literary evocations of Caribbean women's struggle with issues of displacement and a desire to find place. Her specific focus is the material and spirit dimensions in Erna Brodber's novel, Myal (1988) and Patricia Powell's short-story, "Travelling" (2015). Lutchmansingh seeks to determine how these works frame and position migration within a quest for self-determination and self-discovery. She demonstrates how both writers use Caribbean belief systems and ideas of spirituality to render a sense of how the past affects the present. In Myal the journey into the world of spirit leads to the creation of new mythology through which facts of emancipation and nationhood are themselves mythologized and lead to a way of interrogating how the Caribbean survivor of enslavement remains locked in the past. She argues that the past and its power to 
cripple the psyche is likewise of significance to the short-story, "Travelling" which relates the spirit world as it is embodied in the protagonist and creates immobility to her personal encounters of the city. Lutchmansingh's paper demonstrates how a return to timeless and all-pervasive ancestral presences may lead to an awakening from spiritual paralysis of essentialist and material ideologies.

The Melanau Fisherman, by Christina Yin, brings us to Sarawak on the island of Borneo. In this short story we enter the world of a young woman at the pivotal time of the death of her father. This abrupt change leads to a clash of gender, extended family, culture and occupation. As Christina Yin advises the reader, the Melanau people are an indigenous ethnic group living in the coastal wetlands in the southwestern region of the state of Sarawak. The story is set in the small Melanau town of Mukah known for its sago and fishing industries, but the narrative connects us through threads of education, human relations, memories and desires to the state capital of Kuching in Sarawak and as far as Melbourne in Australia, to Malacca on Peninsular Malaysia and the cosmopolitan city of Singapore. Yet these cities can now only be those of the imagination for the new Melanau fisherman as she stays in Mukah to take over her father's business.

In the prose poem, My City Illusion, Shen Xingzhou evokes the movements of her body through the cities in which she has resided as they are shrouded in memory and the experience of various aural, natural and material environments. The poem opens with the poet's name as it is written in Chinese characters before carrying the reader through different realms that call up imaginary cities. At the ending we return to the Chinese characters which now allow us to see these wanderings and the cities as physical spaces that move from Hangzhou, to Shanghai, to Hong Kong, and for now, rest in Singapore.

Denise B. Dillon, brings us to a post apocalyptic city of the imagination. Set in an anthropogenic future in which a great city mutates into a harsh, tropical wilderness, Dillon engages us in a reading of Atwood's speculative fiction novel, Oryx and Crake (2003). The paper explores the novel's visions of loss and extinction in cultural, linguistic, economic and ecological forms - and of altered forms of survival. Dillon explores the thesis that we already live in a "postnatural world" where human activity has altered the climate. She furthermore takes up the argument that apocalyptic tropes are significant to speculative fiction as they act to arouse readers' imaginations and alert people to global environmental threats. Underlying Dillon's analysis is an ecological sensitivity and a move towards understanding human and nature relations. 
Imaginary cities are also the focus of Christopher B. Menadue's paper as he takes us on an exploration of the tropical city as it is imagined in twentieth century science fiction cover art. For his investigation, Menadue used mixed digital and traditional humanities methods to identify and describe cover images of science fiction that portray cities or city-like structures - for instance spaceships - in tropical otherworld settings. His findings demonstrate that there is a substantive portrayal of indigenous peoples through a primitivist trope as possessing less advanced technology than human earthlings in the interplanetary tropics. Depictions of women are notably sexualized or simplistic. Overall the otherworldly tropics - whether jungle or dessert - are portrayed as a place of conflict and a colonial mythology is perpetuated in cover art. A significant realisation for future sci-fi analysis that arose during his research is how the concept of the tropics is itself based on arbitrary, earthly, cartographic conventions, which do not exist on other worlds. Menadue alerts us to the value-laden meaning of tropical environments and societies that is applied by the 'alien,' whether European colonist or visiting Earthling, onto local peoples and places.

From sci-fi cover art we are brought back to earthly concrete structures of the city as Katja Fleischmann and Robert $\mathrm{H}$. Mann take us on a tour of wall art across Western Europe, South America and Cuba in the Caribbean. Their focus is on modern day wall art featuring female iconography. They argue that in contemporary times, wall artists present women as subjects of power, renewal and social commentary. Although graffiti is mainly painted by male artists, they note that women graffiti artists are challenging this arena of male dominance and there are ample examples of this women's work on social media. In order to record and analyse the vast material featured in these open air galleries of cities, Fleischmann and Mann present a photo-essay of specific examples of graffiti featuring women with succinct interpretations for each image. Their journey takes the viewer-reader to Paris, Berlin and Venice, then on to Huanchaco, Peru, the hill city of Valparaiso, Chile, and ends on the tropically evocative streets of Havana, Cuba. In crossing the equator and divides between Western Europe, South America and the Caribbean their tour demonstrates how representations of women on walls are influenced by the geography, history, culture and politics of feminine power.

Sneha Chaudhury and Anita Lundberg return us to southeast Asia and the city of Singapore as it strives to transform into a global creative city of the arts. In order to study this phenomenon on the ground, the authors employ a method of ethnographicflânerie. As they explain, ethnography is noted for its engagement with numerous qualitative methods to observe social practices and interactions while the classic theory of the flâneur provides an added perspective, especially pertaining to the changing cityscape. However, they point out that flânerie warrants critique, firstly in regards to the 
geographical location of cities studied, which have overwhelmingly been located in northern metropoles; and secondly in regards to gender, as the flâneur supports a masculine gaze and subjectivity. Thus their paper explores a tropical city of the global south from the perspective of the female flâneuse with the aim of contributing to the figure of la flâneuse tropique. From their urban peregrinations, Chaudhury and Lundberg present two vignettes in the form of thick descriptions. The first is their experience of a heritage tour of Peranakan houses that morphed into art installation critiquing colonial and global consumerism; the second is an encounter with two images from the growing street art movement. The images are of women - literally on the street - painted by a women's graffiti syndicate.

In the final paper, Gemma Blackwood takes us to Australia's northern-most tropical city of Darwin as it is portrayed through film. A small city positioned at the continent's 'top end' and surrounded by unique natural beauty, the city has had a strong presence in both the Australian and international touristic imagination as a destination of tropical escape. However, Blackwood argues, in Australian cinematic representations, the city of Darwin is often presented as a cultural and natural frontier zone. Through a indepth textual reading of the city's representation in two recent high profile Australian feature films, Blackwood demonstrates how Darwin is rendered as special and distinctive in the national imaginary - albeit in unexpected ways that disrupt the touristic imagination. She details how the two chosen films, Charlie's Country (Rolf de Heer, 2013) and Last Cab to Darwin (Jeremy Sims, 2015), employ compassionate and humanistic themes, with a strong focus on the main characters as they find themselves marginalized and neglected within the broader social systems of Australian society. For each film, she demonstrates how Darwin as a tropical city located in the faraway top end operates as a space of difference - at the ethical frontiers of both legislation and of human sovereignty.

This special issue of eTropic has been concerned with the tropical imaginary as it arises through the living city. Cities are never merely material structures; they are simultaneously imagined. From the imagination cities may be conceived, born, grow, transform - and they can deform, die and disappear - to perhaps be reborn. Intrinsic to this special issue is a call for a renewed sense of the importance of the imagination and how it contributes to life - including the life of the city and of the tropics. These papers have taken up this call in order to explore tropical cities of the imagination - whether they be earthly places, spaces of apocalyptic vision, science-fiction fantasy, colonial machinations, spectral hauntings, mythological (re)creations or embodied practice. It is our hope they provide spaces in which the reader can, likewise, imaginatively engage. 


\section{References}

Lundberg, A. (2018). Living Cities: Tropical Imaginaries. eTropic: electronic journal of studies in the tropics. 17 (1), 1-5. http://dx.doi.org/10.25120/etropic.17.1.2018.3638

Lundberg, A. (2008). Material poetics of a Malay house. The Australian Journal of Anthropology, 19(1), 1-16. https://doi.org/10.1111/1.1835-9310.2008.tb00102.x 